\title{
Genome-wide methylation profiles in monozygotic twins with discordance for ovarian carcinoma
}

\author{
OZGE SUKRUOGLU ERDOGAN, SEREF BUGRA TUNCER, SEDA KILIC, DEMET AKDENIZ ODEMIS, \\ GOZDE KURU TURKCAN, BETUL CELIK, MUKADDES AVSAR and HULYA YAZICI
}

\begin{abstract}
Department of Basic Oncology, Cancer Genetics Division, Institute of Oncology, Istanbul University, Istanbul 34093, Turkey
\end{abstract}
Received March 12, 2020; Accepted August 19, 2020

DOI: $10.3892 / \mathrm{ol} .2020 .12221$

\begin{abstract}
Ovarian cancer is a disease that is generally diagnosed at an advanced stage, and has poor survival. Monozygotic (MZ) twins are considered to be good research models for investigating the epigenetic changes associated with diseases. In the present study, the involvement of epigenetic mechanisms in ovarian cancer etiology were evaluated using the MZ twin model. Whole-genome methylation patterns were investigated in a $B R C A 1$ gene mutation-carrying family comprising $\mathrm{MZ}$ twins, only one of whom had ovarian cancer, and other healthy siblings. Whole-genome methylation patterns were assessed in peripheral blood DNA using Infinium MethylationEPIC BeadChips on an Illumina iScan device. The hypermethylated and hypomethylated genes were detected between cases and controls in four different comparison groups in order to evaluate the differences in methylation levels according to cancer diagnosis and $B R C A$ mutation status. The obtained results showed that the differential methylations in 12 different genes, namely PR/SET domain 6, cytochrome B5 reductase 4, ZNF714, OR52M1, SEMA4D, CHDIL, CAPZB, clustered mitochondria homolog, RB-binding protein 7 , chromatin repair factor, ankyrin repeat domain 23 , RIB43A domain with coiled-coils 1 and C6orf 227, were associated with ovarian cancer. Biological functional analysis of the genes detected in the study using the PANTHER classification system revealed that they have roles in biological processes including 'biologic adhesion', 'regulation', 'cellular components organization', 'biogenesis', 'immune system functioning', 'metabolic functioning' and 'localization'. Overall, the present study suggested that epigenetic differences, such as methylation status, could
\end{abstract}

Correspondence to: Professor Hulya Yazici or Dr Ozge Sukruoglu Erdogan, Department of Basic Oncology, Cancer Genetics Division, Institute of Oncology, Istanbul University, 118 Turgut Ozal Millet Caddesi, Fatih, Istanbul 34093, Turkey

E-mail: hy2188@istanbul.edu.tr; hulyayazici67@gmail.com

E-mail: ozge.erdogan@istanbul.edu.tr

Abbreviations: MZ, monozygotic; NGS, next generation sequencing

Key words: monozygotic twins, whole-genome DNA methylation, epithelial ovarian cancer, $B R C A 1$ gene mutation, epigenetics be used as a non-invasive biological markers for the early diagnosis and follow-up of ovarian cancer.

\section{Introduction}

Ovarian cancer is the eighth most commonly diagnosed cancer in women after breast, colorectal, lung and uterine cancer (1). Ovarian cancer is a disease has poor survival and generally diagnosed at advanced stage. According to the SEER database, the 5 -year relative survival rate for invasive epithelial ovarian cancer between 2009 and 2015 was $47 \%$ (2). Ovaries consist of different types of cells, including germ cells, specified gonadal stromal cells and epithelial cells. Epithelial ovarian cancers constitute the majority of ovarian cancers, and are responsible for the most ovarian cancer-associated deaths $(3,4)$. Early detection of ovarian cancer is difficult due to the lack of ovarian cancer-specific non-invasive molecular biomarkers. Early diagnosis is highly important for treatment and survival in ovarian cancer (5).

Genetic predisposition is known to have a role in breast and gynecological cancer. The cancer susceptibility risk of an individual is associated with genetic predisposition in addition to factors such as reproduction history, the use of oral contraceptives and hormone replacement, radiation exposure in the early period of life, alcohol consumption and physical activity (6). Among a number of risk evaluation models, mutations in breast-ovarian cancer syndrome-associated $B R C A l$ or $B R C A 2$ genes, and mutations in Lynch II syndrome-associated DNA repair genes have been identified as risk factors (7-10). Mutations in BRCA1 and BRCA2 genes and mutations in mismatch repair genes (Lynch syndrome) are among the most common causes of hereditary ovarian cancer syndromes (11). DNA methylation is an epigenetic mechanism that is important in the regulation of gene expression. Epigenetic changes that affect gene expression without causing a structural alteration in the DNA sequence have been shown to play a role in cancer development (12). Monozygotic (MZ) twins with $100 \%$ identical genetic structure are known to be good research models for identifying the association between environmental factors and epigenetic changes in the occurrence of diseases (13). MZ twins share the same genotype, but their phenotypic features may differ. Discordance has been detected in some multifactorial diseases in MZ twin siblings $(14,15)$. The mechanism underlying this discordance between MZ twins has been suggested to involve epigenetic modifications (16). 
Various studies have been conducted using twins to investigate the links between complex diseases and genetic structure, and the effects of environmental factors on those associations. In the first large-scale study on DNA methylation in twins, $20 \mathrm{MZ}$ and 20 dizygotic twin couples were compared. Similar epigenetic profiles and high epigenetic inheritance were observed in the MZ twins in the study; however, epigenetic variation was found to increase with advanced age (17). High-resolution DNA methylation analyses have detected tissue-specific variations and characterized the epigenetic meta-stability of $\sim 6,000$ unique genomic regions in MZ twins $(18,19)$. Phenotypic differences have been shown to develop via epigenetic mechanisms in MZ twin siblings with the same genotype (13).

In the present study, differences in methylation were investigated in the whole genome of MZ twins with a pathogenic BRCA1 mutation, one of whom was healthy while the other was diagnosed with ovarian cancer. The genomic methylation levels of the twins were compared with those of their three BRCA1-mutated sisters and one healthy brother. The findings suggest that epigenetic differences based on methylation status could be used as non-invasive biological markers for the early diagnosis and follow-up of ovarian cancer.

\section{Materials and methods}

BRCA1 and BRCA2 mutation screening. Six siblings who presented to the cancer genetics clinic at the Institute of Oncology, Istanbul University in 2012 for $B R C A 1$ and $B R C A 2$ mutation testing were included in the study. Each individual signed an informed consent form. The study was approved by the Ethics Board of Istanbul University (approval no. 1552, dated May 18, 2015) in accordance with The Declaration of Helsinki (20).

DNA samples isolated from the peripheral blood lymphocytes of the six siblings were used in the study. Genomic DNA was isolated with a QIAamp DNA Mini QIAcube kit (cat. no./ID: 51326) using the QIAcube automated nucleic acid extraction system (both Qiagen N.V.). The integrity of the isolated DNA was measured with the Invitrogen Qubit 4 Fluorometer (Thermo Fisher Scientific, Inc). The BRCA MASTR Plus Dx (cat. no. MR-2015.024; Multiplicom N.V., Agilent Technologies $\mathrm{GmbH}$ ) kit was used for sequencing on the Illumina MiSeq next generation sequencing (NGS) platform (Illumina, Inc.) with paired end libraries. Each reaction was conducted using $10 \mathrm{ng}$ DNA. All BRCAl and BRCA2 coding regions, including 50-bp intron-exon junctions, were covered with the BRCA MASTR Plus Dx kit. Sequencing was performed with 200x coverage. During the run, the presence of small indel mutations and large deletions and duplications was also investigated and evaluated. The sequencing run was performed using MiSeq Reagent kit v2 (cat. no. MS-102-2003; Illumina, Inc.). Sequencing data were analyzed with the SOPHiA $^{\mathrm{TM}}$ DDM clinical NGS data analysis platform (v4; Sophia Genetics).

Methylation differences were evaluated among the six siblings, who comprised $\mathrm{MZ}$ twins both with $B R C A 1$ pathogenic mutations but discordant for ovarian cancer, three sisters with BRCA1 mutations, and one healthy brother with non-mutated $B R C A 1$. The data and codes of the individuals are presented in Table I, and their family tree is shown in Fig. 1.
Four different comparison groups were generated, each containing a case and control group, in order to evaluate the differences in methylation levels according to diagnosis and $B R C A$ mutation conditions. These groups were as follows: Group 1, MZ twin siblings with and without ovarian cancer; Group 2, the MZ twin with ovarian cancer and healthy non-twin siblings; Group 3, all siblings with the BRCA1 mutation and the sibling with no BRCA1 mutation; and Group 4, the healthy MZ twin, and all other healthy siblings. The groups and the codes of individuals in the groups are presented in Table II.

The $\mathrm{CpG}$ islands at which differences in methylation level were detected between the case and control groups according to ovarian cancer etiology and BRCAl mutation-carrying status were compared and evaluated. The methylation differences between the groups were evaluated as 10 -fold and in some groups as 25 -fold or more to obtain more specific regions.

Preparation of the samples and data analysis. Following isolation of the DNA, bisulfite modification was performed for a 500-ng DNA sample in each case. The bisulfite conversions of DNA samples were conducted using the EZ DNA Methylation Kit (cat. no. \#D5001; Zymo Research Corp.).

The genome-level methylation profiles of the modified DNA samples were investigated using the Infinium MethylationEPIC BeadChip Array on an iScan device (Illumina, Inc). The Infinium MethylationEPIC Array is a genome-wide DNA methylation analysis system based on bisulfite conversion and Infinium HD sequencing technology that queries differentiated loci using region-specific probes designed for methylated and non-methylated regions. The total methylation level for a queried locus is determined by calculating the ratio of fluorescent signals from the methylated and unmethylated regions (21). Data analyses of the experimental results were conducted using the Lumi libraries within the Illumina GenomeStudio v2011.1 Methylation Module v1.9.0 (https://www.illumina.com/techniques/microarrays/array-dataanalysis-experimental-design/genomestudio.html) and $\mathrm{R}$ 3.0.2 (http://www.r-project.org). The differences in methylation for $>850,000$ regions on a point basis were investigated using this chip system. All six cases in the study group were evaluated at $>850,000$ different $\mathrm{CpG}$ points.

Pre-processing and quality control of the samples. Background corrections and dye bias equalization filtering, transformation and normalization of the data were conducted using library(lumi) in $\mathrm{R}$ 3.0.2 and were performed to minimize the rate of possible systematic statistical error. After filtering all samples by P-value, a mean of $866,309.3$ CpG regions were identified by $\mathrm{P}<0.01$ and $866,518.5 \mathrm{CpG}$ regions were identified by $\mathrm{P}<0.05$. Probes were regarded as erroneous and excluded from the $\mathrm{CpG}$ analysis when no detection could be taken from the same probe in $>25 \%$ of all samples $(\mathrm{P} \geq 0.05)$.

Probes readable in all samples or having only 1 sample with no readable value were included in the analysis, and the other probes were filtered out (Fig. 2). Accordingly, a total of $563 \mathrm{CpG}$ regions that were found to have insignificant results according to their detection P-value were excluded from the analysis. Thus, $866,332 \mathrm{CpG}$ regions were analyzed in 
Table I. Baseline information of the study participants.

\begin{tabular}{lclll}
\hline Sample code & Age (years) & Sex & \multicolumn{1}{c}{ Diagnosis } & \\
\hline BR 987 & 43 & Female & Ovarian cancer & HET c.5266dupC p.Gln1756Profs*74 rs397507247 \\
BR988 & 43 & Female & Healthy & HET c.5266dupC p.Gln1756Profs*74 rs397507247 \\
BR1446 & 44 & Female & Healthy & HET c.5266dupC p.Gln1756Profs*74 rs397507247 \\
BR1546 & 37 & Female & Healthy & HET c.5266dupC p.Gln1756Profs*74 rs397507247 \\
BR1849 & 32 & Male & Healthy & BRCA1 wild type \\
BR2030 & 46 & Female & Healthy & HET c.5266dupC p.Gln1756Profs*74 rs397507247
\end{tabular}

Table II. Sample codes of participants in the comparison groups.

\begin{tabular}{lll}
\hline Group & \multicolumn{1}{c}{ Case } & \multicolumn{1}{c}{ Control } \\
\hline 1 & BR987 & BR988 \\
2 & BR987 & BR2030, BR1446, BR1546, BR1849 \\
3 & BR987, BR988, BR2030, BR1446, BR1546 & BR1849 \\
4 & BR988 & BR2030, BR1446, BR1546, BR1849
\end{tabular}

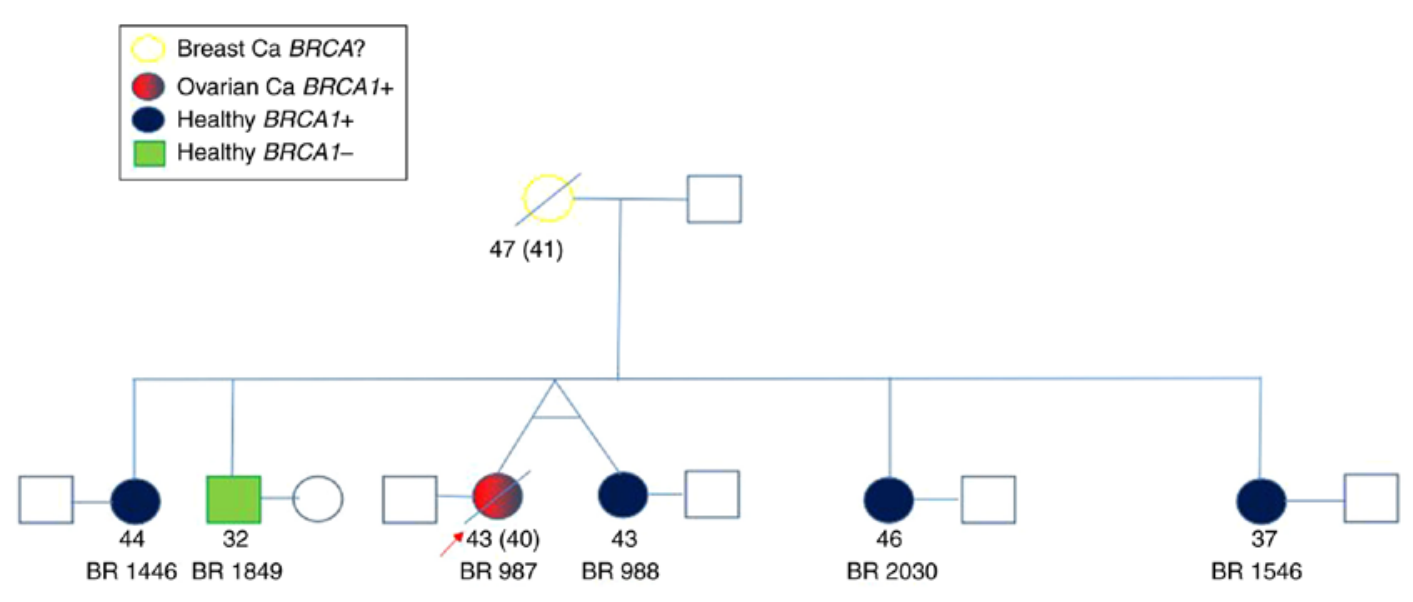

Figure 1. Family tree of the siblings. Ca, cancer. Ages of the individuals at the time of enrolment are presented, and the ages presented with circles and a line indicate the age of death. Ages in brackets indicate the age of diagnosis.

accordance with the Beta Mixture Quantile (BMIQ) normalization procedure using the BMIQ function in R 3.0.2 (22).

Data quality control. Boxplot and density diagrams were drawn for comparison of the distributions before and after BMIQ normalization and data conversion to avoid false results and reduce systematic bias.

A rating diagram was prepared to observe the degree of repetitiveness between the samples using the M-value with Pearson's correlation. The M-value is calculated as the $\log 2$ ratio of the densities of the methylated probe and the unmethylated probe (23). The interval of this rating diagram was established to provide a correlation coefficient (r) of $-1 \leq \mathrm{r} \leq 1$. The samples were identified to have a strong positive correlation if $r$ was close to +1 . Our samples were identified as $r=0.99$ with strong positive correlation.

A dendrogram was drawn using M-values for the samples grouped using hierarchical clustering with Euclidean distance and complete linkage methods (Fig. 3). The diseased and healthy MZ twins were classified together into one group in accordance with the Euclidean distance clustering approach, and the other 4 healthy siblings were classified into a separate group. Investigation of the healthy siblings showed that the $B R C A$ negative brother was classified into a different group from the $B R C A$ mutation-carrying sisters. After clustering with the Euclidean distance method, methylation expression levels were analyzed in the aforementioned case and control groups. The differences between these groups were investigated with regard to two different aspects, namely association with disease and the presence of $B R C A 1$ mutation.

Functional association analysis between genes and proteins. Protein-protein interaction (PPI) analysis provides new data on protein functions and the general organizational principles of functional cellular networks (24). The STRING scores are 


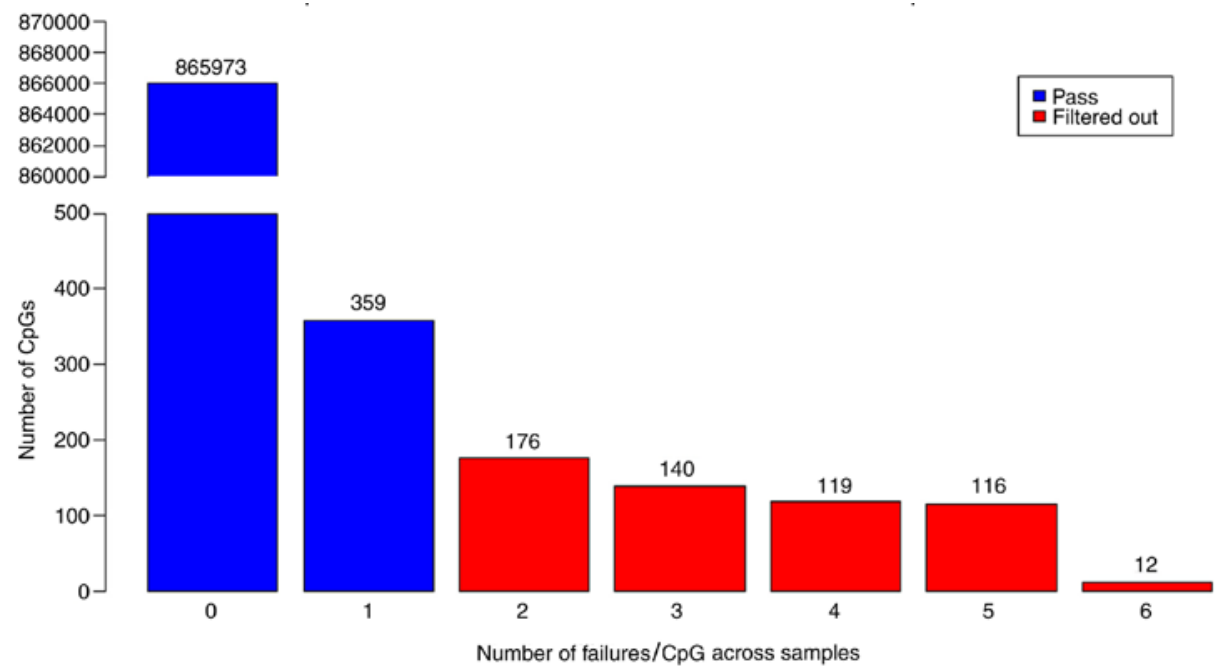

Figure 2. Quality distribution diagram of the accurately readable and unreadable $\mathrm{CpG}$ probes $(\mathrm{P} \geq 0.05)$. The distribution of the number of $\mathrm{CpGs}$ with a detection P-value $\geq 0.05$ is shown. Blue indicates $\mathrm{CpG}$ probes with results that met the quality standard, and red indicates CpG probes that did not meet the quality standard and were excluded from the evaluation. A total of $563 \mathrm{CpGs}$ with detection P-values $\geq 0.05$ across $>25 \%$ of all samples were excluded, leaving $866,332 \mathrm{CpGs}$ to be analyzed.

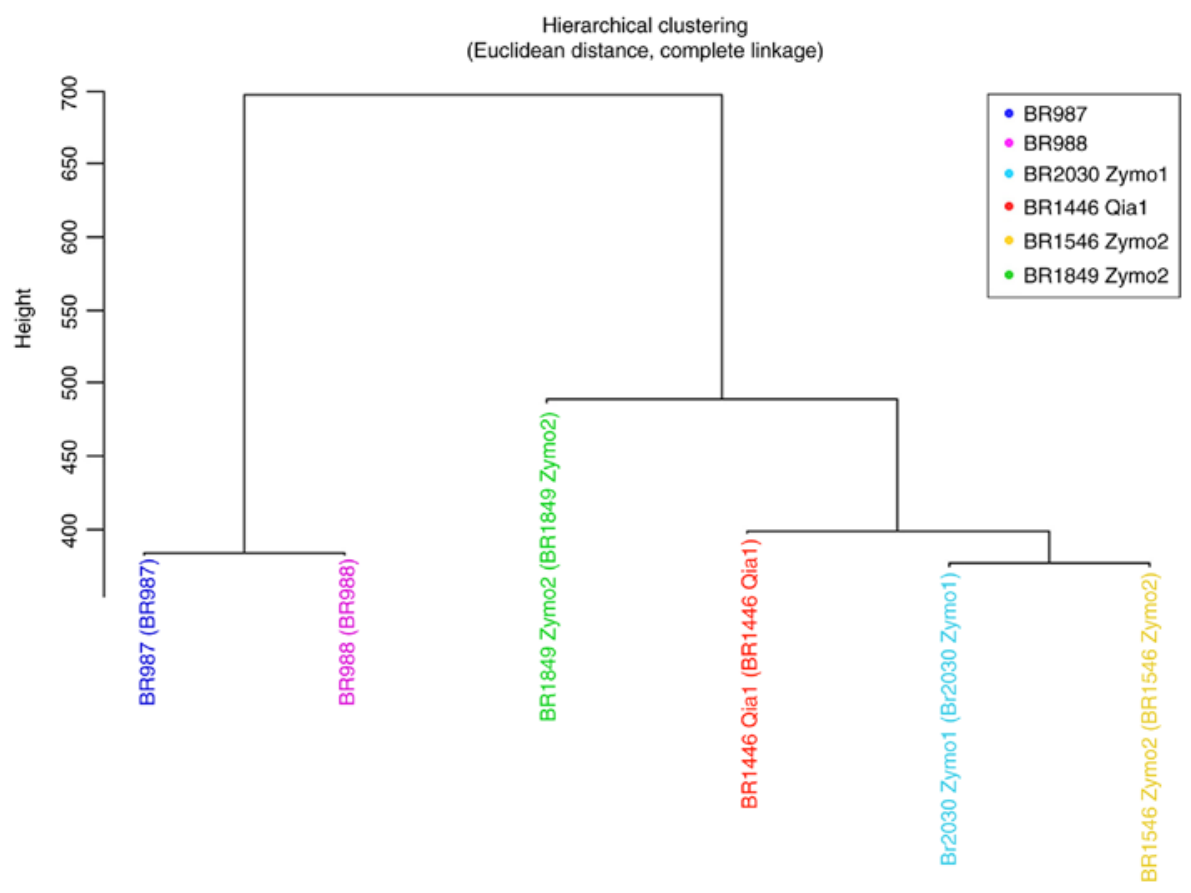

Figure 3. Classification of the samples using hierarchical clustering, and the proximity of the siblings in accordance with these classifications.

indicators of confidence and rank from 0 to 1 , with 1 being the highest possible confidence (25).

Biological function analyses. The biological functions of the genes were evaluated using the Protein Analysis Through Evolutionary Relationships (PANTHER) classification system, which is designed to classify proteins and genes according to their functions (26).

\section{Results}

DNA samples from six individuals from the same family with ovarian cancer risk were analyzed. BRCA1 and BRCA2 gene analyses were performed, and the presence of mutations in certain members of the family was demonstrated. The mutation was detected to be the HET c.5266dupC p.GIn1756Profs*74 rs397507247 mutation in exon 20 of the BRCAl gene.

Differences in methylation levels in the comparison groups. The sites with variations in methylation levels were identified in four different comparison groups for analysis according to diagnosis and BRCAl mutation conditions.

The regions that were identified to have $>10$-fold differences in methylation levels by comparison of the MZ twins that were discordant for the presence of ovarian cancer in Group 1 are presented in Table III. In the MZ 
Table III. Genes with methylation differences between the discordant monozygotic twins.

\begin{tabular}{|c|c|c|c|c|c|c|}
\hline CpG no. & FC value & Chromosome & $\begin{array}{c}\text { UCSC } \\
\text { RefGene }\end{array}$ & $\begin{array}{l}\text { UCSC RefGene } \\
\text { group }\end{array}$ & $\begin{array}{l}\text { Regulatory } \\
\text { characteristic }\end{array}$ & Methylation \\
\hline $\operatorname{cg} 07490070$ & 11.71 & 2 & ANKRD23 & Body & Promoter associated & Hypermethylated \\
\hline $\operatorname{cg} 10632209$ & 17.60 & 5 & PRDM6 & Body & Unclassified & Hypermethylated \\
\hline $\operatorname{cg} 04329454$ & 11.30 & 6 & C6orf227 & Body & Unclassified & Hypermethylated \\
\hline $\operatorname{cg} 22356173$ & 11.02 & 17 & CLUH & 5'UTR & - & Hypermethylated \\
\hline $\operatorname{cg} 20246257$ & 10.45 & $X$ & $R B B P 7$ & TSS1500, TSS200 & Promoter associated & Hypermethylated \\
\hline $\operatorname{cg} 16978043$ & 11.49 & $X$ & $R B B P 7$ & TSS200 & Promoter associated & Hypermethylated \\
\hline $\operatorname{cg} 17880859$ & 11.81 & $\mathrm{X}$ & $R B B P 7$ & 1stExon, 5'UTR & Promoter associated & Hypermethylated \\
\hline $\operatorname{cg} 11449070$ & 11.42 & $X$ & $R I B C 1$ & TSS200, TSS 1500 & Promoter associated & Hypermethylated \\
\hline $\operatorname{cg} 26130726$ & -11.39 & 6 & CYB5R4 & Body & Promoter associated & Hypomethylated \\
\hline
\end{tabular}

FC, fold change; UCSC, University of California, Santa Cruz; UTR, untranslated region; TSS, transcription start site.

twin with ovarian cancer, hypermethylation was detected in the promoter region of the PR/SET domain 6 (PRDM6) (NM_001136239), RB-binding protein 7, chromatin repair factor $(R B B P 7)$ (NM_002893), ankyrin repeat domain 23 (ANKRD23) (NM_144994), RIB43A domain with coiled-coils 1 (RIBC1) (NM_001031745), C6orf 227 (NR_027908) and clustered mitochondria homolog (CLUH) (NM_015229) genes, and hypomethylation was detected in the promoter region of the cytochrome B5 reductase 4 (CYB5R4) (NM_016230) gene. The sites of hypermethylation were located in $\mathrm{CpG}$ islets of the RBBP7, ANKRD23, RIBC1 and $C 6$ orf 227 genes, and the northern $(\mathrm{N})$ shore region of the $C L U H$ gene, while the $C Y B 5 R 4$ gene was hypomethylated in the southern $(\mathrm{S})$ shore region.

The regions with $>10$-fold difference in methylation levels when the MZ twin with ovarian cancer was compared with the other healthy siblings in Group 2 are presented in Table IV. The differentially methylated sites of the genes were as follows: RPL9, LIAS and CYP2U1 in CpG islets; ACTN3 and ZFA in S shelf regions; $M Y C B P$, GJA9 and SEMA4D in S shore regions; and ZNF714, OR4D and CLUH in N shore regions.

Regions with $>10$-fold hypomethylation and with $>25$-fold hypermethylation (there were too many regions over 10 -fold in this group, therefore 25-fold was used, for which more specific regions should be given) when the $B R C A 1$ positive cases were compared with the BRCA1 negative case in Group 3 are presented in Table $\mathrm{V}$. The hypermethylation sites of genes $P Q B P 1, T I M M 17 B, F M R 1$ and AIFM1 were located in $\mathrm{CpG}$ islets, while those of the ARHGEF9, AR and RPL36A genes were in $\mathrm{N}$ shore regions. The TSC22D3 and DOCK11 genes were found to be hypermethylated at $\mathrm{S}$ shore sites.

The regions with $>10$-fold differences in methylation levels when the healthy MZ twin was compared with the other healthy siblings in Group 4 are presented in Table VI. With regard to hypomethylated sites, those of RPL9, LIAS and PRDM6 were located in CpG islets, ACTN3 and ZFAT were in $\mathrm{S}$ shelf regions, MYCBP, GJA9 and KLHL36 were in $\mathrm{S}$ shore regions, and $O R 4 D 1$ was in the $\mathrm{N}$ shore region. The CYP2U1 gene was hypermethylated on $\mathrm{CpG}$ islets, the LOC25 3724 gene was hypermethylated in the $\mathrm{S}$ shelf region, and the $C Y B 5 R 4$ gene was hypermethylated in the $\mathrm{S}$ shore region.
Evaluation of the comparisons between groups. Comparison of the MZ twin with ovarian cancer and the healthy MZ twin (Group 1) showed that the PRDM6 gene was hypermethylated in the MZ twin with ovarian cancer. However, PRDM6 was found to be hypomethylated in the healthy MZ twin compared with the other healthy siblings (Group 4). The CYB5R4 gene was demonstrated to be hypomethylated in the MZ twin with ovarian cancer compared with the healthy MZ twin (Group 1), but hypermethylated in the healthy MZ twin compared with the other healthy siblings (Group 4). Furthermore, the CYB5R4 gene was found to be hypermethylated in all healthy individuals, regardless of whether they were negative or positive for the BRCA1 mutation (Group 3). The genes RPL9, LIAS, TGFBI, ACTN3, SLC2A1-AS1, MYCBP, GJA9, KLHL36, LUZP1, HDAC4, OR4D1, UPF1, SHANK2, TG, FBXW12, FAM114A2, DYRK4, SLC25A13 and ZFAT were found to be hypomethylated in the MZ twin with ovarian cancer compared with the non-twin healthy siblings (Group 2) and the healthy MZ twin compared with the other healthy siblings (Group 4), while the genes TRIO, DNTTIP2, HIVEP2, CTNND2, CASQ2, C9orf171, FLNB, C7orf45, ACOT11, CYP2U, and ITIH3 were found to be hypermethylated in these comparison groups.

The genes RBBP7, ANKRD23, RIBC1, C6orf 227 and $C L U H$ were hypermethylated in the $\mathrm{MZ}$ twin with ovarian cancer compared with the healthy MZ twin (Group 1), while the CYB5R4 gene was hypomethylated. The ZNF714, OR52M1 and $S E M A 4 D$ genes were observed to be hypomethylated, while the $C H D 1 L, C A P Z B$ and $C L U H$ genes were hypermethylated in the $\mathrm{MZ}$ twin with ovarian cancer compared with non-twin healthy siblings (Group 2). Evaluation of the results obtained from all the comparison groups in the present study suggests that the methylation conditions of the PRDM6, CYB5R4, ZNF714, OR52M1, SEMA4D, CHD1L, CAPZB, $C L U H, R B B P 7, A N K R D 23, R I B C$ and C6orf 227 genes may be effective for the differentiation of ovarian cancer.

The comparison of $B R C A 1$ positive and $B R C A 1$ negative cases (Group 3) showed that the genes $N A D K 2, K R T 38$, KIAA0513, ASAM, FNDC1, GSDMA, SFT2D1, C5orf33, CD24, TTTY14, TXNDC16, XG and TRAPPC12 were hypomethylated, and the genes CXorf26, FAM122C, ARHGEF9, PQBP1, TIMM17B, FMR1, AR, AIFM1, TSC22D3, RPL36A 
Table IV. Genes demonstrating methylation differences between the monozygotic twin diagnosed with ovarian cancer and healthy siblings.

\begin{tabular}{|c|c|c|c|c|c|c|}
\hline CpG no. & FC value & Chromosome & $\begin{array}{c}\text { UCSC } \\
\text { RefGene }\end{array}$ & $\begin{array}{l}\text { UCSC RefGene } \\
\text { group }\end{array}$ & $\begin{array}{l}\text { Regulatory } \\
\text { characteristic }\end{array}$ & Methylation \\
\hline $\operatorname{cg} 01802772$ & 14.69 & 1 & ACOT11 & Body & Unclassified & Hypermethylated \\
\hline $\operatorname{cg} 10767615$ & 10.36 & 1 & $C A P Z B$ & Body, 5'UTR & - & Hypermethylated \\
\hline $\operatorname{cg} 06279067$ & 12.44 & 1 & CASQ2 & Body & - & Hypermethylated \\
\hline $\operatorname{cg} 13324406$ & 10.18 & 1 & CHD1L & Body & - & Hypermethylated \\
\hline $\operatorname{cg} 03544800$ & 11.11 & 1 & DNTTIP2 & Body & - & Hypermethylated \\
\hline $\operatorname{cg} 10195365$ & 12.94 & 3 & $F L N B$ & Body & - & Hypermethylated \\
\hline $\operatorname{cg} 05393861$ & 16.12 & 3 & ITIH3 & TSS200 & - & Hypermethylated \\
\hline $\operatorname{cg} 17004290$ & 15.06 & 4 & $C Y P 2 U 1$ & Body & Promoter associated & Hypermethylated \\
\hline $\operatorname{cg} 16104636$ & 12.30 & 5 & CTNND2 & Body, 5'UTR & - & Hypermethylated \\
\hline $\operatorname{cg} 07611121$ & 10.12 & 5 & TRIO & Body & - & Hypermethylated \\
\hline $\operatorname{cg} 10613215$ & 11.44 & 6 & HIVEP2 & 5'UTR & Promoter associated & Hypermethylated \\
\hline $\operatorname{cg} 12134602$ & 13.53 & 7 & C7orf45 & 3'UTR & - & Hypermethylated \\
\hline $\operatorname{cg} 21499289$ & 12.72 & 9 & C9orf171 & Body & - & Hypermethylated \\
\hline $\operatorname{cg} 22356173$ & 15.03 & 17 & $C L U H$ & 5'UTR & - & Hypermethylated \\
\hline $\operatorname{cg} 09255886$ & -14.88 & 1 & $L U Z P 1$ & 5'UTR & - & Hypomethylated \\
\hline $\operatorname{cg} 24051749$ & -17.15 & 1 & МYCВP;GJA9 & TSS1500, body & - & Hypomethylated \\
\hline $\operatorname{cg} 03967651$ & -17.55 & 1 & $S L C 2 A 1-A S 1$ & Body & - & Hypomethylated \\
\hline $\operatorname{cg} 00409995$ & -14.51 & 2 & HDAC4 & Body & - & Hypomethylated \\
\hline $\operatorname{cg} 03192919$ & -12.31 & 3 & $F B X W 12$ & TSS 1500 & - & Hypomethylated \\
\hline $\operatorname{cg} 19311470$ & -26.28 & 4 & RPL9,LIAS & $\begin{array}{l}\text { TSS150, 5'UTR, } \\
\text { TSS200, TSS200 }\end{array}$ & Promoter associated & Hypomethylated \\
\hline $\operatorname{cg} 15421137$ & -11.74 & 5 & FAM114A2 & 3'UTR & - & Hypomethylated \\
\hline $\operatorname{cg} 17386240$ & -21.99 & 5 & $T G F B I$ & Body & - & Hypomethylated \\
\hline $\operatorname{cg} 16792234$ & -10.42 & 7 & $S L C 25 A 13$ & Body & - & Hypomethylated \\
\hline $\operatorname{cg} 10584449$ & -12.97 & 8 & $T G$ & Body & - & Hypomethylated \\
\hline $\operatorname{cg} 21927991$ & -10.03 & 8 & $Z F A T$ & Body & - & Hypomethylated \\
\hline $\operatorname{cg} 21203249$ & -10.19 & 9 & SEMA4D & Body & $\begin{array}{l}\text { Gene associated cell } \\
\text { type specific }\end{array}$ & Hypomethylated \\
\hline $\operatorname{cg} 12208638$ & -18.40 & 11 & ACTN3 & Body & - & Hypomethylated \\
\hline $\operatorname{cg} 27079096$ & -14.59 & 11 & OR52B4 & TSS200 & - & Hypomethylated \\
\hline $\operatorname{cg} 17040924$ & -10.63 & 11 & OR52M1 & TSS1500 & - & Hypomethylated \\
\hline $\operatorname{cg} 14167033$ & -13.45 & 11 & SHANK2 & Body & - & Hypomethylated \\
\hline $\operatorname{cg} 09581911$ & -11.28 & 12 & DYRK4 & TSS200 & Promoter associated & Hypomethylated \\
\hline $\operatorname{cg} 00645020$ & -16.70 & 16 & KLHL36 & Body & - & Hypomethylated \\
\hline $\operatorname{cg} 11189272$ & $-14,04$ & 17 & OR4D1 & 1stExon & - & Hypomethylated \\
\hline $\operatorname{cg} 01462799$ & $-13,84$ & 19 & $U P F 1$ & Body & - & Hypomethylated \\
\hline $\operatorname{cg} 19882830$ & $-11,24$ & 19 & ZNF714 & TSS200 & - & Hypomethylated \\
\hline $\operatorname{cg} 01483656$ & $-14,22$ & 19 & ZNF714 & TSS200 & Promoter associated & Hypomethylated \\
\hline
\end{tabular}

FC, fold change; UCSC, University of California, Santa Cruz; UTR, untranslated region; TSS, transcription start site.

and DOCK11 were hypermethylated between the comparison groups. These methylation changes may be associated with the presence or absence of the $B R C A l$ gene mutation.

Functional association analysis between genes and proteins. A PPI network was established in the present study to analyze the functions of the proteins encoded by the differentially methylated genes. The experimental data and the STRING functional protein association network v.10.5, which provides data on estimated interactions, was used in the analysis of the interactions. The protein network obtained was shown to have significantly higher protein interaction than expected ( $\mathrm{P}=0.000331$; Fig. 4). Two more STRING analyses were performed, which reported connections between $C A P Z B$ and $F L N B$, and BRCA 1 and $A R$ (data not shown). 
Table V. Genes demonstrating methylation differences between the $B R C A 1$ positive and negative cases.

\begin{tabular}{|c|c|c|c|c|c|c|}
\hline CpG no. & FC value & Chromosome & $\begin{array}{l}\text { UCSC } \\
\text { RefGene }\end{array}$ & $\begin{array}{l}\text { UCSC RefGene } \\
\text { group }\end{array}$ & $\begin{array}{l}\text { Regulatory } \\
\text { characteristic }\end{array}$ & Methylation \\
\hline $\operatorname{cg} 27519679$ & 27.84 & $\mathrm{X}$ & AIFMI & 1stExon & Promoter associated & Hypermethylated \\
\hline $\operatorname{cg} 19493242$ & 27.70 & $\mathrm{X}$ & $A R$ & 1stExon & - & Hypermethylated \\
\hline $\operatorname{cg} 06316979$ & 25.69 & $X$ & ARHGEF9 & 1stExon, 5'UTR, body & - & Hypermethylated \\
\hline $\operatorname{cg} 00723034$ & 25.00 & $X$ & CXorf26 & Body & - & Hypermethylated \\
\hline $\operatorname{cg} 18785414$ & 32.78 & $X$ & DOCK 11 & Body & Promoter associated & Hypermethylated \\
\hline $\operatorname{cg} 14972002$ & 25.23 & $X$ & FAM122C & TSS200, body & Promoter associated & Hypermethylated \\
\hline $\operatorname{cg} 17430903$ & 26.33 & $\mathrm{X}$ & FMR1 & TSS200 & Promoter associated & Hypermethylated \\
\hline $\operatorname{cg} 14332086$ & 26.22 & $\mathrm{X}$ & $\begin{array}{l}P Q B P 1 \\
T I M M 17 B\end{array}$ & $\begin{array}{l}\text { TSS } 1500, \text { TSS200, } \\
\text { 5'UTR }\end{array}$ & Promoter associated & Hypermethylated \\
\hline $\operatorname{cg} 00029931$ & 30.19 & $\mathrm{X}$ & RPL36A & TSS 1500 & Promoter associated & Hypermethylated \\
\hline $\operatorname{cg} 13801593$ & 29.57 & $\mathrm{X}$ & $T S C 22 D 3$ & $\begin{array}{l}\text { Body, 1stExon, } \\
\text { TSS } 1500,5 \text { 'UTR }\end{array}$ & Promoter associated & Hypermethylated \\
\hline $\operatorname{cg} 17018422$ & -10.25 & 2 & TRAPPC12 & Body & - & Hypomethylated \\
\hline $\operatorname{cg} 09819502$ & -11.41 & 5 & C5orf33 & TSS 1500 & - & Hypomethylated \\
\hline $\operatorname{cg} 03966322$ & -15.68 & 5 & $N A D K 2$ & TSS 1500, TSS200 & - & Hypomethylated \\
\hline $\operatorname{cg} 14022523$ & -11.83 & 6 & SFT2D1 & TSS200 & Promoter associated & Hypomethylated \\
\hline $\operatorname{cg} 10637509$ & -13.34 & 6 & FNDC1 & Body & - & Hypomethylated \\
\hline $\operatorname{cg} 18847598$ & -13.65 & 11 & $A S A M$ & Body & - & Hypomethylated \\
\hline $\operatorname{cg} 07541959$ & -11.05 & 14 & TXNDC16 & Body & - & Hypomethylated \\
\hline $\operatorname{cg} 05522042$ & -13.87 & 16 & KIAA0513 & 3'UTR & $\begin{array}{l}\text { Unclassified cell } \\
\text { type specific }\end{array}$ & Hypomethylated \\
\hline $\operatorname{cg} 06589596$ & -12.87 & 17 & GSDMA & 5'UTR & - & Hypomethylated \\
\hline $\operatorname{cg} 25929399$ & -14.06 & 17 & KRT38 & TSS200 & - & Hypomethylated \\
\hline $\operatorname{cg} 13176022$ & -10.47 & $\mathrm{X}$ & $X G$ & Body & Unclassified & Hypomethylated \\
\hline $\operatorname{cg} 02351050$ & -10.89 & $\mathrm{Y}$ & $\begin{array}{l}\text { CD24; } \\
\text { TTTY14 }\end{array}$ & $\begin{array}{l}\text { 1stExon, body, 5'UTR, } \\
\text { TSS } 1500, \text { TSS } 200\end{array}$ & $\begin{array}{l}\text { Unclassified cell } \\
\text { type specific }\end{array}$ & Hypomethylated \\
\hline $\operatorname{cg} 23654549$ & -10.88 & Y & $\begin{array}{l}\text { CD24; } \\
\text { TTTY14 }\end{array}$ & $\begin{array}{l}\text { 1stExon, body, } \\
\text { TSS200, 5'UTR }\end{array}$ & - & Hypomethylated \\
\hline $\operatorname{cg} 16227841$ & -10.68 & $\mathrm{Y}$ & $\begin{array}{l}\text { CD24; } \\
\text { TTTY14 }\end{array}$ & $\begin{array}{l}\text { 1stExon, body, } \\
\text { TSS200, 5'UTR }\end{array}$ & - & Hypomethylated \\
\hline $\operatorname{cg} 01150227$ & -10.46 & $\mathrm{Y}$ & $\begin{array}{l}\text { CD24; } \\
\text { TTTY14 }\end{array}$ & $\begin{array}{l}\text { 1stExon, body, 5'UTR, } \\
\text { TSS1500, TSS200 }\end{array}$ & $\begin{array}{l}\text { Unclassified cell } \\
\text { type specific }\end{array}$ & Hypomethylated \\
\hline $\operatorname{cg} 14683071$ & -11.20 & $\mathrm{Y}$ & $\begin{array}{l}\text { CD24; } \\
\text { TTTY14 }\end{array}$ & $\begin{array}{l}\text { 1stExon, body, } \\
\text { TSS200, 5'UTR }\end{array}$ & - & Hypomethylated \\
\hline
\end{tabular}

FC, fold change; UCSC, University of California, Santa Cruz; UTR, untranslated region; TSS, transcription start site.

Biological function analyses. The results of the PANTHER analysis revealed that the genes identified in the study had roles in biological processes including 'biologic adhesion', 'regulation', 'cellular components organization' and 'biogenesis', 'immune system functioning', 'metabolic functioning' and 'localization'. Also, these genes were found to have roles in molecular functions including 'attachment', 'catalytic activity', 'receptor activity', 'signal transmission' and 'translational regulation'.

\section{Discussion}

Although there have been promising developments in cancer studies in recent years, data on the biological basis of ovarian cancer are limited. All cancers develop as a consequence of the accumulation of genetic changes or other molecular disorders such as epigenetic changes. Epigenetic and genetic changes are known to contribute to the development of ovarian cancer. Epigenetic studies on ovarian cancer have demonstrated the role of epigenetics in ovarian cancer development, and its association with various signaling pathways (27-29). DNA methylation detected in the $\mathrm{CpG}$ islands of the promoter regions of genes associated with the development of cancer has been found to be frequently associated with the reduced expression or silencing of those genes (27).

Researchers investigating methylation in $\mathrm{MZ}$ twins demonstrated that age and other non-genetic factors triggered epigenetic variations and provided strong evidence for epigenetic inheritance $(18,19)$. Therefore, the present study 
Table VI. Genes demonstrating methylation differences between the healthy monozygotic twin, and the other healthy siblings.

\begin{tabular}{|c|c|c|c|c|c|c|}
\hline CpG no & FC value & Chromosome & $\begin{array}{c}\text { UCSC } \\
\text { RefGene }\end{array}$ & $\begin{array}{l}\text { UCSC RefGene } \\
\text { group }\end{array}$ & $\begin{array}{c}\text { Regulatory } \\
\text { characteristics }\end{array}$ & Methylation \\
\hline cg01802772 & 14.00 & 1 & ACOT11 & Body & Unclassified & Hypermethylated \\
\hline cg06279067 & 11.58 & 1 & $C A S Q 2$ & Body & - & Hypermethylated \\
\hline $\operatorname{cg} 03544800$ & 11.26 & 1 & DNTTIP2 & Body & - & Hypermethylated \\
\hline $\operatorname{cg} 10195365$ & 13.63 & 3 & $F L N B$ & Body & - & Hypermethylated \\
\hline $\operatorname{cg} 09371091$ & 10.17 & 3 & $H R H 1$ & 5'UTR & - & Hypermethylated \\
\hline $\operatorname{cg} 05393861$ & 15.47 & 3 & ITIH3 & TSS200 & - & Hypermethylated \\
\hline $\operatorname{cg} 17004290$ & 16.01 & 4 & $C Y P 2 U 1$ & Body & Promoter associated & Hypermethylated \\
\hline $\operatorname{cg} 16104636$ & 12.17 & 5 & CTNND2 & Body, 5'UTR & - & Hypermethylated \\
\hline $\operatorname{cg} 07611121$ & 10.00 & 5 & TRIO & Body & - & Hypermethylated \\
\hline $\operatorname{cg} 26130726$ & 14.50 & 6 & CYB5R4 & Body & Promoter associated & Hypermethylated \\
\hline $\operatorname{cg} 10613215$ & 13.24 & 6 & HIVEP2 & 5'UTR & Promoter associated & Hypermethylated \\
\hline $\operatorname{cg} 12134602$ & 13.58 & 7 & C7orf45 & 3'UTR & - & Hypermethylated \\
\hline $\operatorname{cg} 21499289$ & 12.73 & 9 & C9orf171 & Body & - & Hypermethylated \\
\hline $\operatorname{cg} 13815695$ & 10.72 & 12 & LOC253724 & Body & - & Hypermethylated \\
\hline $\operatorname{cg} 09255886$ & -14.51 & 1 & $L U Z P 1$ & 5'UTR & - & Hypomethylated \\
\hline $\operatorname{cg} 24051749$ & -14.41 & 1 & МYCВP;GJA9 & TSS1500, body & - & Hypomethylated \\
\hline $\operatorname{cg} 03967651$ & -18.79 & 1 & $S L C 2 A 1-A S 1$ & Body & - & Hypomethylated \\
\hline cg00409995 & -14.53 & 2 & $H D A C 4$ & Body & - & Hypomethylated \\
\hline $\operatorname{cg} 01427108$ & -11.99 & 3 & $L T F$ & Body & - & Hypomethylated \\
\hline $\operatorname{cg} 03192919$ & -12.55 & 3 & $F B X W 12$ & TSS 1500 & - & Hypomethylated \\
\hline $\operatorname{cg} 16570885$ & -11.45 & 3 & $I G F 2 B P 2$ & Body & - & Hypomethylated \\
\hline $\operatorname{cg} 19311470$ & -20.13 & 4 & RPL9;LIAS & $\begin{array}{l}\text { TSS } 1500, \\
5 \text { 'UTR, TSS200 }\end{array}$ & Promoter associated & Hypomethylated \\
\hline $\operatorname{cg} 15421137$ & -11.62 & 5 & $F A M 114 A 2$ & 3'UTR & - & Hypomethylated \\
\hline $\operatorname{cg} 10632209$ & -17.03 & 5 & PRDM6 & Body & $\begin{array}{l}\text { Unclassified cell } \\
\text { type specific }\end{array}$ & Hypomethylated \\
\hline $\operatorname{cg} 17386240$ & -17.46 & 5 & $T G F B I$ & Body & - & Hypomethylated \\
\hline $\operatorname{cg} 16792234$ & -11.71 & 7 & $S L C 25 A 13$ & Body & - & Hypomethylated \\
\hline $\operatorname{cg} 10584449$ & -13.63 & 8 & $T G$ & Body & - & Hypomethylated \\
\hline cg21927991 & -10.92 & 8 & $Z F A T$ & Body & - & Hypomethylated \\
\hline $\operatorname{cg} 12208638$ & -18.53 & 11 & $A C T N 3$ & Body & - & Hypomethylated \\
\hline $\operatorname{cg} 14167033$ & -16.07 & 11 & SHANK2 & Body & - & Hypomethylated \\
\hline $\operatorname{cg} 27079096$ & -14.72 & 11 & OR52B4 & TSS200 & - & Hypomethylated \\
\hline cg00474091 & -11.18 & 12 & $A E B P 2$ & Body & - & Hypomethylated \\
\hline $\operatorname{cg} 09581911$ & -11.28 & 12 & $D Y R K 4$ & TSS200 & - & Hypomethylated \\
\hline $\operatorname{cg} 00645020$ & -13.81 & 16 & KLHL36 & Body & - & Hypomethylated \\
\hline $\operatorname{cg} 11189272$ & -13.02 & 17 & $O R 4 D 1$ & 1stExon & - & Hypomethylated \\
\hline $\operatorname{cg} 01462799$ & -11.99 & 19 & $U P F 1$ & Body & - & Hypomethylated \\
\hline
\end{tabular}

FC, fold change; UCSC, University of California, Santa Cruz; UTR, untranslated region; TSS, transcription start site.

investigated genome level methylation differences among MZ twins with BRCAl gene mutations, one with ovarian cancer and one without, and their healthy siblings in the present study. The potential effects of the differentially methylated genes and their association with ovarian cancer were investigated. Some of the significantly differentially hypermethylated and hypomethylated genes that were identified in the methylation analyses conducted in the present study were consistent with those in previous studies.
In the present study, promoter hypermethylation of the genes PRDM6, RBBP7, ANKRD23, RIBC1, C6orf 227 and $C L U H$ was identified in the $\mathrm{MZ}$ twin with ovarian cancer compared with the healthy $\mathrm{MZ}$ twin. PRDM6 encodes a protein that binds to nucleic acid and has a histone-lysine $\mathrm{N}$-methyltransferase activity. PRDM6 is a transcription factor associated with enzymes that have roles in chromatin remodeling and gene expression, including heterochromatin protein-1, histone deacetylase (HDAC)1, HDAC2 and HDAC3, 


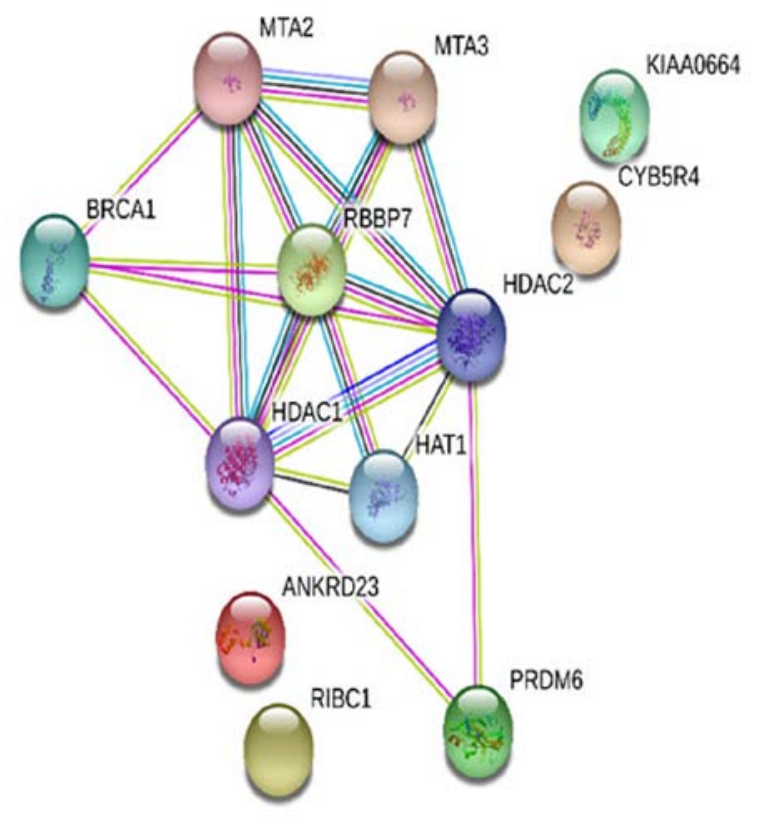

Figure 4. Protein association network for the genes that showed differential methylation levels in monozygotic twins with the BRCA1 mutation.

histone acetyltransferase p300 and histone methyltransferase G9a (30). The STRING analysis in the present study showed that PRDM6 was associated with HDAC1 and HDAC2, which themselves bound to BRCA1 and RBBP7 proteins. We suggest that the PRDM6 gene is specific to ovarian cancer because the PRDM6 gene was hypermethylated in the MZ twin with cancer compared with the healthy MZ twin, but hypomethylated in the healthy MZ twin compared with other healthy siblings. The STRING analysis indicates that the effect of this molecule in the development of ovarian cancer may be mediated through HDAC and BRCA1 proteins. The carriers of the $B R C A 1$ mutation in the present study, and the methylation changes between the $\mathrm{MZ}$ twins and other siblings who were discordant for ovarian cancer supports STRING analysis. The PRDM6 gene was hypermethylated in the MZ twin with cancer compared with the healthy MZ twin, but hypomethylated in the healthy MZ twin compared with other healthy siblings.

The RBBP7 gene encodes a highly expressed protected nuclear protein that directly binds to retinoblastoma protein and thereby regulates cell proliferation. Retinoblastoma and retinal cancers are associated with $R B B P 7$ (31). BRCAl has been shown to interact in vivo and in vitro with the $\mathrm{Rb}$-binding proteins RBBP7 (also known as RbAp4) and RbAp48 (31). The effect of the BRCAl gene on various processes, including transcription, DNA repair and recombination, has been explained by the association of BRCA1 with HDAC1 and HDAC2 (31). A >10-fold higher hypermethylation of the $R B B P 7$ gene was detected in the MZ twin with cancer compared with the healthy twin. The STRING analysis performed in this group suggests that RBBP7 interacts with the BRCA1 tumor suppressor protein, thus resulting in the development of ovarian cancer via roles in the regulation of cellular proliferation and differentiation. In addition, $R B B P 7$ has previously been shown to have NF-kB modulating, NOTCH1-associated pathway and HDAC activities by Kyoto Encyclopedia of Genes and Genomes (KEGG) pathway analysis. These activities have been reported to serve a role in different cancers (32).

Detection of hypomethylation of the CYB5R4 gene in the MZ twin with ovarian cancer compared with the healthy MZ twin, and hypermethylation in all healthy siblings regardless of BRCAl mutation status suggests that hypomethylation of $C Y B 5 R 4$ gene might be involved in the development of ovarian cancer. Although the effect of the CYB5R4 gene is unclear in cancer, this gene has been reported to be mutated in patients with breast cancer (33).

VEGF has been shown to suppress the expression of Semaphorin 4D (SEMA4D) in epithelial ovarian cancer tissues (34). In the present study, ZNF714, OR52M1 and SEMA4D genes were found to be hypomethylated in the MZ twin with ovarian cancer compared with the non-twin healthy siblings. This suggests that the hypomethylation of SEMA4D may be associated with ovarian cancer. The overexpression of CHD1L protein has been reported to be associated with metastasis in ovarian cancer, and CHD1L protein expression evaluated using immunohistochemistry has been suggested be a new prognostic biomarker for patients with ovarian cancer (35). The observation of $C H D 1 L$ hypermethylation in the twin with ovarian cancer compared with the non-twin healthy siblings, in contrast with the literature, suggests that the development of ovarian cancer might occur with the suppression of CHDIL expression.

In the STRING analysis conducted in the present study, a connection was identified between $C A P Z B$ and $F L N B$. In a previous study, the $\mathrm{CpG}$ regions with different FLNB DNA methylation levels between men and women were identified. The genes with higher methylation in either sex were subjected to KEGG pathway analysis. The 'cell adhesion molecules' pathway was enriched with genes having a higher methylation level in women, and the 'adipocytokine signaling pathway' was enriched with genes having a higher methylation level in men (36). In another study, FLNB was shown to be inhibited by mir-223, let-7d and mir-130a (37). The miRNA molecules shown to inhibit the FLNB gene in the previous study were found to have high expression levels in MZ twin siblings with ovarian cancer in another study conducted by our group (unpublished data).

NADK2, KRT38, KIAA0513, ASAM, FNDC1, GSDMA, SFT2D1, C5orf33,CD24, TTTY14, TXNDC16, XG and TRAPPC12 genes were hypomethylated, and CXorf26, FAM122C, ARHGEF9, PQBP1, TIMM17B, FMR1, AR, AIFM1, TSC22D3, RPL36A and DOCK11 genes were hypermethylated in the siblings with the $B R C A 1$ mutation compared with the sibling with wild-type $B R C A 1$. It has been suggested that the determined genes are completely related to wild-type BRCA1 because they have different gene profiles according to the comparisons. These genes are completely different from the genes detected in the other comparison groups. An association was detected between $B R C A I$ and $A R$ proteins in the STRING analysis. Previous studies reported that $A R$ promoter hypermethylation was associated with decreased AR expression in breast cancer cell lines (38), and that $A R$ gene promoter methylation was higher in patients with wild-type $B R C A 1 / 2$ compared with mutated $B R C A 1 / 2$ in men diagnosed with breast cancer (39). In general, the data in the literature indicate that $A R$ is associated with male breast cancer (39). The 
detection of hypermethylated $A R$ in the brother with wild-type $B R C A 1$ in the present study is consistent with the literature.

The present study was performed using the peripheral blood lymphocytes of $B R C A 1$ mutation carrying discordant $\mathrm{MZ}$ twins and other healthy siblings with and without BRCAl mutation. Therefore, the study has a limitation that no methylation analysis was performed in the tissues of the $\mathrm{MZ}$ twins or the siblings who underwent preventive surgery. However, we plan to investigate the expression and methylation of these genes in these tissues and in larger ovarian cancer patient cohorts in future studies.

The results obtained in the present study suggest that the differential methylation of 12 different genes, namely PRDM6, CYB5R4, ZNF714, OR52M1, SEMA4D, CHD1L, CAPZB, CLUH, RBBP7, ANKRD23, RIBC1 and C6orf227 might be associated with the development of ovarian cancer. Also, we suggest that the differential methylation levels of 24 genes, namely NADK2, KRT38, KIAA0513, ASAM, FNDC1, GSDMA, SFT2D1, C5orf33, CD24; TTTY14, TXNDC16, XG, TRAPPC12, CXorf26, FAM122C, ARHGEF9, PQBP1, TIMM17B, FMR1, $A R, A I F M 1, T S C 22 D 3, R P L 36 A$ and DOCK11 are associated with the $B R C A 1$ mutation. To the best of our knowledge, the present study is the first to report the effect of methylation differences in the full genome in ovarian cancer. The comparison of the identified genes in larger ovarian cancer patient cohorts, in benign ovarian disease, and a population-based healthy cohort, and an investigation of the mRNA and protein expression levels of these genes would be appropriate in the future.

\section{Acknowledgements}

Not applicable.

\section{Funding}

This study was supported by the Scientific Research Projects Unit of Istanbul University (project no. 59477). In the study, the funding body has no role in the preparation, data collection, analysis and interpretation of the manuscript.

\section{Availability of data and materials}

The datasets generated and/or analyzed during the current study are not publicly available due to restrictions of the Local and Clinical Research Ethics Committee of Istanbul University to protect patient privacy.

\section{Authors' contributions}

Conceptualization and methodology, OSE and HY; formal analysis of the data, OSE, SK, DAO, SBT, GKT, BC and MA; writing the original draft of the manuscript, OSE, SK, DAO, SBT, GKT, BC and MA; writing, reviewing and editing the manuscript, OSE and HY; visualization, supervision, scientific contribution and criticism, HY. All authors read and approved the final manuscript.

\section{Ethics approval and consent to participate}

This study complies with ethical standards WMA Declaration of Helsinki-Ethical Principles for Medical Research Involving human subjects) (20). The Ethics Board of Istanbul University granted approval for the study to be conducted in the Department of Basic Oncology, Istanbul University, Institute of Oncology (approval date May 18, 2015; approval no. 1552). All patients were informed about the study and granted consent in the scope of the cancer genetics polyclinic.

\section{Patient consent for publication}

Individual consent was signed by each sibling.

\section{Competing interests}

The authors declare that they have no competing interests.

\section{References}

1. Bray F, Ferlay J, Soerjomataram I, Siegel RL, Torre LA and Jemal A: Global cancer statistics 2018: GLOBOCAN estimates of incidence and mortality worldwide for 36 cancers in 185 countries. CA Cancer J Clin 68: 394-424, 2018.

2. Noone AM, Krapcho M, Miller D, Brest A, Yu M, Ruhl J, Tatalovich Z, Mariotto A, Lewis DR, Chen HS, et al (eds): SEER Cancer statistics review. National Cancer Institute Bethesda, MD 1975-2015.

3. Yancik R: Ovarian cancer. Age contrasts in incidence, histology, disease stage at diagnosis, and mortality. Cancer 71: 517-523, 1993.

4. Kurman RJ: Origin and molecular pathogenesis of ovarian high-grade serous carcinoma. Ann Oncol 24 (Suppl 10): x16-x21, 2013.

5. US Preventive Services Task Force, Bibbins-Domingo K, Grossman DC, Curry SJ, Barry MJ, Davidson KW, Doubeni CA, Epling JW Jr, García FA, Kemper AR, et al: Screening for gynecologic conditions with pelvic examination: US preventive services task force recommendation statement. JAMA 317: 947-953, 2017.

6. La Vecchia C: Ovarian cancer: Epidemiology and risk factors. Eur J Cancer Prev 26: 55-62, 2017.

7. Whittemore AS, Harris R and Itnyre J: Characteristics relating to ovarian cancer risk: Collaborative analysis of 12 US case-control studies. II. Invasive epithelial ovarian cancers in white women. Collaborative Ovarian Cancer Group. Am J Epidemiol 136: 1184-1203, 1992.

8. Pharoah PD, Day NE, Duffy S, Easton DF and Ponder BA: Family history and the risk of breast cancer: A systematic review and meta-analysis. Int J Cancer 71: 800-809, 1997.

9. Crum CP, Drapkin R, Miron A, Ince TA, Muto M, Kindelberger DW and Lee Y: The distal fallopian tube: A new model for pelvic serous carcinogenesis. Curr Opin Obstet Gynecol 19: 3-9, 2007.

10. Kurman RJ and McConnell TG: Characterization and comparison of precursors of ovarian and endometrial carcinoma: Parts I and II. Int J Surg Pathol 18 (Suppl 3): S181-S189, 2010.

11. Mutch D, Denny L and Quinn M; FIGO Committee on Gynecologic Oncology: Hereditary gynecologic cancers. Int J Gynaecol Obstet 124: 189-192, 2014.

12. Wolffe AP and Matzke MA: Epigenetics: Regulation through repression. Science 286: 481-486, 1999.

13. Chatterjee A and Morison IM: Monozygotic twins: Genes are not the destiny? Bioinformation 7: 369-370, 2011.

14. Ready K, Litton JK and Arun BK: Clinical application of breast cancer risk assessment models. Future Oncol 6: 355-365, 2010.

15. Petronis A, Gottesman II, Kan P, Kennedy JL, Basile VS, Paterson AD and Popendikyte V: Monozygotic twins exhibit numerous epigenetic differences: Clues to twin discordance? Schizophr Bull 29: 169-178, 2003.

16. Wong AH, Gottesman II and Petronis A: Phenotypic differences in genetically identical organisms: The epigenetic perspective. Hum Mol Genet 14 Spec No 1: R11-R18, 2005.

17. Fraga MF, Ballestar E, Paz MF, Ropero S, Setien F, Ballestar ML, Heine-Suñer D, Cigudosa JC, Urioste M, Benitez J, et al: Epigenetic differences arise during the lifetime of monozygotic twins. Proc Natl Acad Sci USA 102: 10604-10609, 2005. 
18. Heijmans BT, Kremer D, Tobi EW, Boomsma DI and Slagboom PE: Heritable rather than age-related environmental and stochastic factors dominate variation in DNA methylation of the human IGF2/H19 locus. Hum Mol Genet 16: 547-554, 2007.

19. Kaminsky ZA, Tang T, Wang SC, Ptak C, Oh GH, Wong AH Feldcamp LA, Virtanen C, Halfvarson J, Tysk C, et al: DNA methylation profiles in monozygotic and dizygotic twins. Nat Genet 41: 240-245, 2009.

20. The Helsinki Declaration of the World Medical Association (WMA): Ethical principles of medical research involving human subjects. Pol Merkur Lekarski 36: 298-301, 2014 (In Polish).

21. Pidsley R, Zotenko E, Peters TJ, Lawrence MG, Risbridger GP Molloy P, Van Djik S, Muhlhausler B, Stirzaker C and Clark SJ: Critical evaluation of the Illumina MethylationEPIC BeadChip microarray for whole-genome DNA methylation profiling. Genome Biol 17: 208, 2016.

22. Teschendorff AE, Marabita F, Lechner M, Bartlett T, Tegner J, Gomez-Cabrero D and Beck S: A beta-mixture quantile normalization method for correcting probe design bias in Illumina Infinium 450 k DNA methylation data. Bioinformatics 29 : 189-196, 2013

23. Du P, Zhang X, Huang CC, Jafari N, Kibbe WA, Hou L and Lin SM: Comparison of Beta-value and M-value methods for quantifying methylation levels by microarray analysis. BMC Bioinformatics 11: 587, 2010.

24. Stelzl U, Worm U, Lalowski M, Haenig C, Brembeck FH, Goehler H, Stroedicke M, Zenkner M, Schoenherr A, Koeppen S, et al: A human protein-protein interaction network: A resource for annotating the proteome. Cell 122: 957-968, 2005.

25. Szklarczyk D, Gable AL, Lyon D, Junge A, Wyder S, Huerta-Cepas J, Simonovic M, Doncheva NT, Morris JH, Bork P, et al: STRING v11: Protein-protein association networks with increased coverage, supporting functional discovery in genome-wide experimental datasets. Nucleic Acids Res 47: D607-D613, 2019.

26. Thomas PD, Kejariwal A, Campbell MJ, Mi H, Diemer K, Guo N, Ladunga I, Ulitsky-Lazareva B, Muruganujan A, Rabkin S, et al: PANTHER: A browsable database of gene products organized by biological function, using curated protein family and subfamily classification. Nucleic Acids Res 31: 334-341, 2003.

27. Jones PA and Baylin SB: The epigenomics of cancer. Cell 128 : 683-692, 2007

28. Zheng M, Hu Y, Gou R, Wang J, Nie X, Li X, Liu Q, Liu J and Lin B: Integrated multi-omics analysis of genomics, epigenomics, and transcriptomics in ovarian carcinoma. Aging (Albany NY) 11: 4198-4215, 2019.
29. Maldonado L and Hoque MO: Epigenomics and ovarian carcinoma. Biomark Med 4: 543-570, 2010.

30. Davis CA, Haberland M, Arnold MA, Sutherland LB McDonald OG, Richardson JA, Childs G, Harris S, Owens GK and Olson EN: PRISM/PRDM6, a transcriptional repressor that promotes the proliferative gene program in smooth muscle cells. Mol Cell Biol 26: 2626-2636, 2006.

31. Yarden RI and Brody LC: BRCA1 interacts with components of the histone deacetylase complex. Proc Natl Acad Sci USA 96: 4983-4988, 1999.

32. Yu N, Zhang P, Wang L, He XJ, Yang SS and Lu HJ: RBBP7 is a prognostic biomarker in patients with esophageal squamous cell carcinoma. Oncol Lett 16: 7204-7211, 2018.

33. Xu M, Wang W, Frontera JR, Neely MC, Lu J, Aires D, Hsu FF, Turk J, Swerdlow RH, Carlson SE and Zhu H: Ncb5or deficiency increases fatty acid catabolism and oxidative stress. J Biol Chem 286: 11141-11154, 2011

34. Chen Y, Zhang L, Liu WX and Wang K: VEGF and SEMA4D have synergistic effects on the promotion of angiogenesis in epithelial ovarian cancer. Cell Mol Biol Lett 23: 2, 2018.

35. He WP, Zhou J, Cai MY, Xiao XS, Liao YJ, Kung HF, Guan XY, Xie D and Yang GF: CHD1L Protein is overexpressed in human ovarian carcinomas and is a novel predictive biomarker for patients survival. BMC Cancer 12: 437, 2012

36. Hall E, Volkov P, Dayeh T, Esguerra JL, Salö S, Eliasson L, Rönn T, Bacos K and Ling C: Sex differences in the genome-wide DNA methylation pattern and impact on gene expression, microRNA levels and insulin secretion in human pancreatic islets. Genome Biol 15: 522, 2014.

37. Chen B and Li CW: Big Mechanisms of aging via system 1dentification and big database mining. In: Big Mechanisms in Systems Biology. Elsevier, pp671-735, 2017.

38. Peters KM, Edwards SL, Nair SS, French JD, Bailey PJ, Salkield K, Stein S, Wagner S, Francis GD, Clark SJ and Brown MA: Androgen receptor expression predicts breast cancer survival: The role of genetic and epigenetic events. BMC Cancer 12: 132, 2012.

39. Rizzolo P, Silvestri V, Valentini V, Zelli V, Zanna I, Masala G, Bianchi S, Palli D and Ottini L: Gene-specific methylation profiles in BRCA-mutation positive and BRCA-mutation negative male breast cancers. Oncotarget 9: 19783-19792, 2018.

This work is licensed under a Creative Commons Attribution-NonCommercial-NoDerivatives 4.0 International (CC BY-NC-ND 4.0) License. 